\title{
PROJETO EDIFICAR: RELATO DE UMA PROFESSORA NA SALA DE AULA DE MATEMÁTICA
}

\author{
PROJETO EDIFICAR: REPORT OF A TEACHER IN THE MATHEMATICS \\ CLASSROOM
}

Cristiane Vieira Pistille dos Santos Matta ${ }^{1}$

Paulo Cesar Oliveira ${ }^{2}$

RESUMO: Neste artigo apresentamos tarefas formuladas por uma professorapesquisadora que desenvolveu com seus alunos dos anos finais do Ensino Fundamental o projeto de construção de uma casa com embalagens de caixa de leite. A motivação para o trabalho com projeto originou do desempenho insatisfatório de alunos em avaliação somativa. O desenvolvimento das atividades dos alunos ocorreu mediante um processo contínuo de avaliação, durante um semestre letivo das aulas de Matemática. Em termos de natureza metodológica optou-se por uma pesquisa qualitativa na modalidade estudo de caso. O objetivo dessa pesquisa foi relacionar as etapas de trabalho no Projeto Edificar com o desempenho dos alunos na avaliação somativa, a partir das produções escritas dos alunos. A análise feita pela professora-pesquisadora na comparação entre a avaliação formativa e somativa em cada turma revelou situações de fracasso escolar.

Palavras-chave: Projeto. Avaliação. Ensino-aprendizagem.

ABSTRACT: In this article, we present tasks formulated by a teacher-researcher, who developed with students of the concluding years of elementary school a project of constructing a house with milk carton packaging. The motivation for working with the project came from the unsatisfactory performance of students in summative assessment. The development of students' activities took place through a continuous evaluation process, during a semester of Mathematics classes. In terms of method nature, qualitative research was chosen in the case study modality. The objective of this research was to relate the work stages in the Edificar Project with the students' performance in the summative assessment, based on the students' written productions. The analysis carried out by the teacher-researcher in the comparison between the formative and summative assessment in each class revealed situations of school failure.

Keywords: Design. Evaluation. Teaching-learning.

\footnotetext{
'Licenciada em Matemática. iDocente da rede estadual de ensino de Sorocaba. E-mail: cristiane.pistille@gmail.com

2 Doutor em Educação Matemática. Professor associado da UFSCar- campus Sorocaba. Email: paulooliveira@ufscar.br.
} 


\section{INTRODUÇÃO}

A educação brasileira norteada por um ensino pautado em competências e habilidades que se referem às expectativas de aprendizagem dos alunos teve seu marco a partir da homologação dos Parâmetros Curriculares Nacionais - PCN (BRASIL, 1998). O foco no desenvolvimento de competências e habilidades tem prevalecido como um dos princípios na construção de nove currículos (AC, BA, MS, PI, RJ, RO, RS, SE e SP), entre dezesseis estados brasileiros, como apontou o estudo realizado pelo Centro de Estudos e Pesquisas em Educação - CENTEC (SÃO PAULO, 2015).

Mais recentemente, tivemos a homologação da Base Nacional Comum Curricular BNCC (BRASIL, 2018), na qual as decisões pedagógicas devem estar orientadas para o desenvolvimento de competências, através da constituição e mobilização de conhecimentos, habilidades, atitudes e valores por parte dos alunos.

O foco no desenvolvimento de competências, de acordo com a BNCC, também é adotado em avaliações internacionais como é o caso da Organização para a Cooperação e Desenvolvimento Econômico - OCDE, que coordena o Programa Internacional de Avaliação de Alunos - Pisa, (BRASIL, 2018).

A BNCC estabelece uma relação com a avaliação da aprendizagem e vínculo com avaliação externa ou de larga escala como o Pisa, de acordo com a seguinte ação proposta: "construir e aplicar procedimentos de avaliação formativa de processo ou de resultado que levem em conta os contextos e as condições de aprendizagem, tomando tais registros como referência para melhorar o desempenho da escola, dos professores e dos alunos" (BRASIL, 2018, p.17).

O documento da BNCC contém dois tipos de propostas de avaliação (formativa e somativa) para "assegurar as aprendizagens essenciais definidas para cada etapa da Educação Básica” (BRASIL, 2018, p.17). Recorremos para Forner e Trevisol (2012, p.246) que distinguiram os dois focos de concentração da avaliação: "o acompanhamento processual do aluno consiste no tipo de avaliação denominado avaliação formativa, enquanto o foco nos resultados consiste no tipo de avaliação que denominamos de avaliação somativa".

Este relato é uma produção acadêmica da linha de pesquisa 'Avaliação: sistemas de larga escala e processos formativos' do Grupo de Estudos e Planejamento de Aulas de Matemática - GEPLAM, um grupo de pesquisa certificado pela UFSCar e composto, em parte, por professores-pesquisadores atuantes nos anos finais do Ensino Fundamental e Ensino Médio, em unidades escolares da rede pública e/ou particular da região metropolitana de Sorocaba, São Paulo.

Apresentamos neste texto etapas do desenvolvimento do Projeto Edificar sob a responsabilidade de uma professora-pesquisadora com seus alunos das turmas de $6^{\circ}$ ao $9^{\underline{O}}$ ano do Ensino Fundamental - EF, envolvidos na resolução de problemas com conteúdos de geometria, de modo a permitir a construção de uma casa feita com embalagens de caixa de leite, apresentada na Figura I 


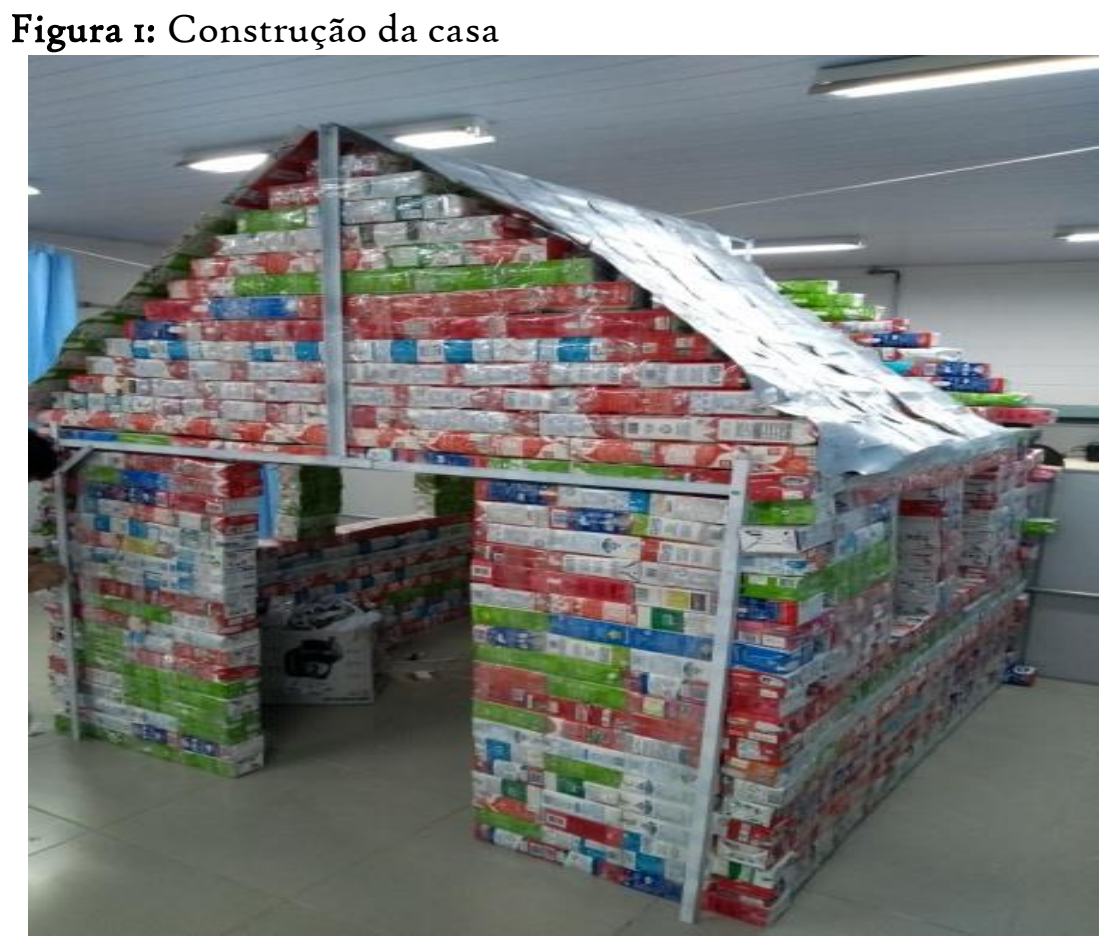

Fonte: acervo do projeto

A motivação para o desenvolvimento do Projeto Edificar, nomeação dada pela professora-pesquisadora, foi decorrente do mau desempenho dos estudantes do 9 o ano EF na Avaliação de Aprendizagem em Processo - AAP, no primeiro e segundo bimestre de 2018 com índices de 40,77\% e 36,11\% de acertos na disciplina de matemática, respectivamente.

A Avaliação de Aprendizagem em Processo, fundamentada nas competências e habilidades do Currículo do Estado de São Paulo (SÃO PAULO, 2012), tem como objetivo disponibilizar ao professor uma ferramenta de diagnóstico acerca do desempenho dos estudantes na disciplina de Matemática e Língua Portuguesa, atualmente em cada um dos três bimestres letivos, para todos os anos do Ensino Fundamental e séries do Ensino Médio.

Essa avaliação também é um exemplo de sistema de avaliação em larga escala como instrumento para a classificação e regulação do desempenho do aluno ao final de um período letivo. Dado o fato que no cotidiano escolar a avaliação formativa e somativa demarcam ações no cumprimento de conteúdos programáticos estabelecidos em cada bimestre, o mau desempenho dos alunos do $9^{\underline{0}}$ ano EF demandou da professorapesquisadora um levantamento de competências e habilidades não atingidas no $\mathrm{I}^{\mathrm{O}} \mathrm{e} 2^{\mathrm{o}}$ bimestre, em todas as turmas dos anos finais do Ensino Fundamental.

O foco no desempenho escolar do $9^{-}$ano EF foi devido à cobrança por resultados adequados desses alunos no final do ano letivo, ao participar do Sistema de Avaliação do Rendimento Escolar do Estado de São Paulo - SARESP, outra avaliação de natureza somativa. 
Com base nos pressupostos de Forner e Trevisol (2012), a professora-pesquisadora acatou que na transição da avaliação somativa para a formativa é fundamental que os resultados apresentados oriente o docente e forneça elementos para que ele possa realizar os ajustes necessários à sua prática pedagógica, transformando as dificuldades apresentadas pelos estudantes em momentos de aprendizagem. Apoiando-se em Chueiri (2008, p.58), quanto à avaliação formativa, independente do padrão metodológico na abordagem dos conteúdos, o objetivo é "levantar informações úteis à regulação do processo de ensinoaprendizagem".

O processo de regulação do ensino-aprendizagem foi norteado pelo trabalho com Projeto, no decorrer de um semestre letivo, o qual envolveu aproximadamente III estudantes, distribuídos em quatro turmas dos anos finais do Ensino Fundamental: $6^{\circ} \mathrm{A}$, $7^{\circ} \mathrm{A}, 8^{\circ} \mathrm{A}$ e $9^{\circ} \mathrm{A}$.

Neste artigo apresentamos as tarefas formuladas pela professora-pesquisadora de Matemática, com o objetivo de relacionar as etapas do trabalho com o Projeto Edificar com o desempenho dos alunos na Avaliação de Aprendizagem em Processo.

Estruturamos a continuidade do texto apresentando o percurso metodológico da pesquisa e as tarefas específicas para cada turma que contribuiu na construção da casa com embalagens de caixas de leite.

\section{PERCURSO METODOLÓGICO DA PESQUISA}

Este estudo seguiu uma abordagem qualitativa, porque se valoriza um processo de ensino em ambiente natural, no caso a observação de atividades matemáticas desenvolvidas por alunos de cada uma turma dos anos finais do Ensino Fundamental, sob a responsabilidade da professora-pesquisadora (CRESWELL, 2010).

O relato dessa experiência pedagógica configura-se como um estudo de caso, por envolver o desenvolvimento de um projeto de ensino e suas implicações em termos de avaliação, com características singulares, no caso, a construção de uma casa utilizando caixas de leite. Destacamos as palavras de Ponte (2006, p.io6) ao caracterizar que o objetivo de um estudo de caso "é compreender em profundidade o 'como' e os 'porquês' dessa entidade", no nosso contexto, o projeto de ensino, "evidenciando a sua identidade e características próprias, nomeadamente nos aspectos que interessam ao pesquisador".

No decorrer do desenvolvimento do 'Projeto Edificar' os instrumentos de coleta de dados foram os protocolos escritos das resoluções individuais das atividades realizadas pelos alunos, fotografias das várias etapas de construção da casa com as embalagens de caixas de leite e observações da professora-pesquisadora.

$\mathrm{O}$ ato de observar o outro esteve centrado na avaliação como processo. Former e Trevisol (2012, p.246) esclarece-nos que "quando observamos alguém durante a realização de uma tarefa, estamos avaliando o processo, isto é, como algo está sendo feito por um sujeito e quais os fenômenos que ocorrem com ele, o sujeito, durante o desenvolvimento da atividade".

A difusão dessa experiência pedagógica também contou com a produção de um vídeo intitulado "Professora de Sorocaba ensina matemática de um jeito diferente e melhora desempenho dos alunos" (RECORD TV PAULISTA, 2018). 
No tecer desta escrita apresentamos a concepção de 'projeto' empregado nesse processo de ensino-aprendizagem. Buscamos trabalhar com projeto por conta que Giordano e Silva (2017) com base na revisão de diversas pesquisas brasileiras revelar que essa abordagem pedagógica contribui para a realização do trabalho cooperativo entre professores e alunos, além de desenvolver por meio da aprendizagem a autonomia dos alunos na realização de tarefas propostas.

Já em relação à pesquisa de Carvalho (2009), apropriamos das reflexões feitas pela autora, com base em resultados de pesquisas realizadas sobre a análise da própria prática pedagógica no desenvolvimento de projetos de ensino. Mais especificamente, destacamos as características expostas por Carvalho (2009) para constituir um trabalho com projetos.

Primeiramente, para Carvalho (2009), o aluno deve participar do projeto desde a definição do tema, planejamento, realização e análise das ações. A ideia da professorapesquisadora era fazer uma maquete e produzir tarefas cujas atividades matemáticas dos alunos subsidiassem o projeto da construção de uma casa. No entanto, por pertencer a um contexto escolar cuja comunidade de pais de alunos, na sua maioria, exercem atividades profissionais no ramo da construção civil (pedreiro ou auxiliar de pedreiro), serralheria, marcenaria ou reciclagem de produtos; os alunos propuseram a construção da casa com materiais recicláveis e tijolos feitos com caixas de leite preenchidas com jornal em seu interior, ao invés da maquete.

A professora-pesquisadora acatou a proposta dos seus alunos e com o apoio da gestão escolar, realizou diversas reuniões com as turmas do Ensino Fundamental (6으, $7^{\mathcal{o}} \mathrm{A}, 8^{\circ} \mathrm{A}$ e $9^{\underline{\mathrm{o}} \mathrm{A}}$ ), Grêmio Estudantil e participantes do programa Escola da Família para adesão às demandas desse trabalho, batizado pela comunidade escolar como 'Projeto Edificar'.Além de oferecer programações culturais e esportivas aos sábados e domingos, as unidades que participam do programa Escola da Família, de acordo com a demanda de cada escola, oferecem oficinas de artesanato, música, beleza, gastronomia, entre outras.

Outra característica importante no trabalho com projetos é a forma usual de constituir pequenos grupos para a realização das tarefas propostas em sala de aula, o que "implica adesão individual e empenho coletivo em cada uma das fases" (CARVALHO, 2009, p.84). No 'Projeto Edificar', formamos grupos de três ou quatro alunos para a realização das tarefas, porém, os registros na forma de protocolos escritos, foram feitos individualmente. Isto se fez necessário para que a professora-pesquisadora pudesse ter elementos para compor o processo de avaliação contínua dos alunos (avaliação formativa).

No decorrer das aulas de matemática da professora-pesquisadora, o desenvolvimento do 'Projeto Edificar' demandou a correção dos cálculos necessários para a construção de cada parte da casa, a participação dos grupos em cada turma com sugestões, questionamentos e dúvidas, além da pontualidade e desempenho nas entregas de atividades, por vezes, como tarefa de casa.

Atividades extra-escolares foram necessárias para promover a exposição da casa construída com as caixas de leite. Muitos alunos das turmas dos anos finais do Ensino Fundamental e Ensino Médio participavam das atividades do programa Escola da Família, juntamente ou não, com seus pais. Nesses encontros, aos finais de semana, inclusive com a participação da professora-pesquisadora, foi-se constituindo um processo colaborativo no qual alunos do Ensino Médio tornaram-se monitores de grupos dos alunos das turmas de 
6으 ao $9^{\circ}$ ano do Ensino Fundamental, ajudando-os na validação dos cálculos efetuados e na concretização da construção da casa.

O Grêmio Estudantil também teve uma atuação nessas atividades extra-escolares, apoiando a campanha para a arrecadação das embalagens de caixas de leite, responsabilidade em cuidar dos materiais arrecadados e utilizados na construção do telhado e paredes, além de ajudar no enchimento de caixas de leite com material reciclável (jornal ou revista) para compor os tijolos e levantar paredes. $O$ registro na Figura 2 ilustra uma das ações desses estudantes com o 'Projeto Edificar':

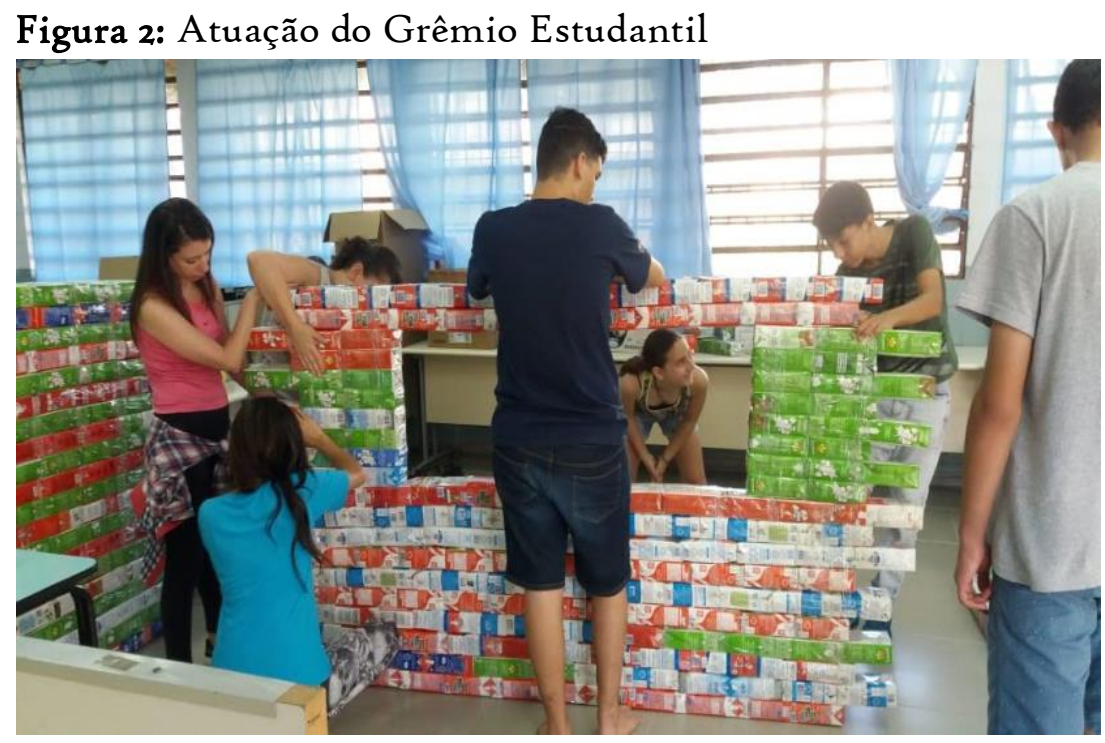

Fonte: acervo do projeto

A seção de 'resultados e discussões na continuidade da redação desse relato traz um panorama do olhar observador da professora-pesquisadora nos dois focos de concentração da avaliação: o processo e o produto/resultado.

\section{RESULTADOS E DISCUSSÕES}

No que diz respeito à avaliação formativa (processo), os alunos de todas as turmas dos anos finais do Ensino Fundamental - EF mostraram-se comprometidos com as tarefas propostas para a concretização do 'Projeto Edificar', revelando um aumento na frequência escolar, melhora no cumprimento e desempenho na resolução das tarefas propostas.

A medida que as tarefas foram sendo propostas, a professora-pesquisadora observou as dificuldades e, em caso, estabeleceu intervenções pedagógicas pertinentes para a aprendizagem dos alunos. Na turma de $6^{\mathrm{o}}$ e $7^{\mathrm{o}}$ ano do $\mathrm{EF}$, por exemplo, para o uso adequado de instrumentos como a régua e a fita métrica, a professora-pesquisadora teve que abordar conexões entre múltiplos e submúltiplos da unidade padrão metro. Esta intervenção pedagógica contribuiu para capacitar os alunos do $6^{\circ}$ ano para lidar com 
noções de área e perímetro de figuras planas. No caso do $7^{\circ}$ ano, foi necessário capacitá-los na aprendizagem de razão e proporção aplicadas em figuras geométricas planas.

Em termos de avaliação somativa, o resultado na Avaliação de Aprendizagem em Processo - AAP do 3ํㅡㄹ bimestre foi insatisfatório, nas duas turmas. A análise da professorapesquisadora quanto ao desempenho desses alunos revelou que os alunos do 60 ano não souberam trabalhar com a noção de área e perímetro associada à malha quadriculada, por exemplo. No caso do $7^{0}$ ano, a AAP privilegiou a noção de razão e proporção com problemas de aritmética.

No caso $8^{\mathrm{o}}$ ano do EF, a professora-pesquisadora avaliou a aprendizagem em atividades envolvendo o emprego das propriedades de simetria (reflexão, rotação e translação), bem como a utilização do material manipulável Geoplano para o cálculo de área envolvendo grandeza discreta (processo de contagem). Houve pouca ênfase no decorrer das aulas de matemática, para um processo de ensino-aprendizagem com conteúdos algébricos. Em termos de avaliação somativa, os alunos não tiveram êxito na $\mathrm{AAP}$, pois a maioria das questões inclusive de natureza geométrica foram propostas articulando-as com expressões algébricas.

$\mathrm{O} 9^{-}$ano do EF foi a turma que obteve melhor rendimento na Avaliação de Aprendizagem em Processo - AAP quando comparado com as demais turmas. A ênfase no estudo do Teorema de Pitágoras e noções básicas de trigonometria em tarefas envolvendo o desenvolvimento do 'Projeto Edificar', no decorrer das aulas de matemática, foram compatíveis com as questões propostas na avaliação somativa. No entanto, o rendimento nas questões objetivas da AAP não foi melhor, pois algumas questões demandaram cálculos envolvendo operações com radiciação.

Nas subseções que segue, selecionamos algumas tarefas propostas em cada turma dos anos finais do Ensino Fundamental, com registros escritos das atividades dos alunos envolvendo a construção do telhado e das paredes com as aberturas para janela e porta. No decorrer da apresentação das tarefas inserimos as competências e habilidades abordadas de acordo com os conteúdos programáticos previstos para o segundo semestre letivo, no Currículo do Estado de São Paulo (SÃO PAULO, 2012). Apresentamos, também, a solução de cada tarefa, as dificuldades observadas pela professora-pesquisadora nas aulas de matemática e o desempenho na Avaliação de Aprendizagem em Processo.

\section{ANO DO ENSINO FUNDAMENTAL}

A turma do 6o ano do Ensino Fundamental recebeu o seguinte problema para resolver: quantas caixas serão necessárias para a construção da casinha?

A resolução da tarefa envolveu o processo de contagem para a construção do telhado e das paredes, levando em conta o espaço destinado para porta e janela.

O formato do telhado pode ser aproximado por um triângulo isósceles (Figura 3): 
Figura 3: Esboço do telhado

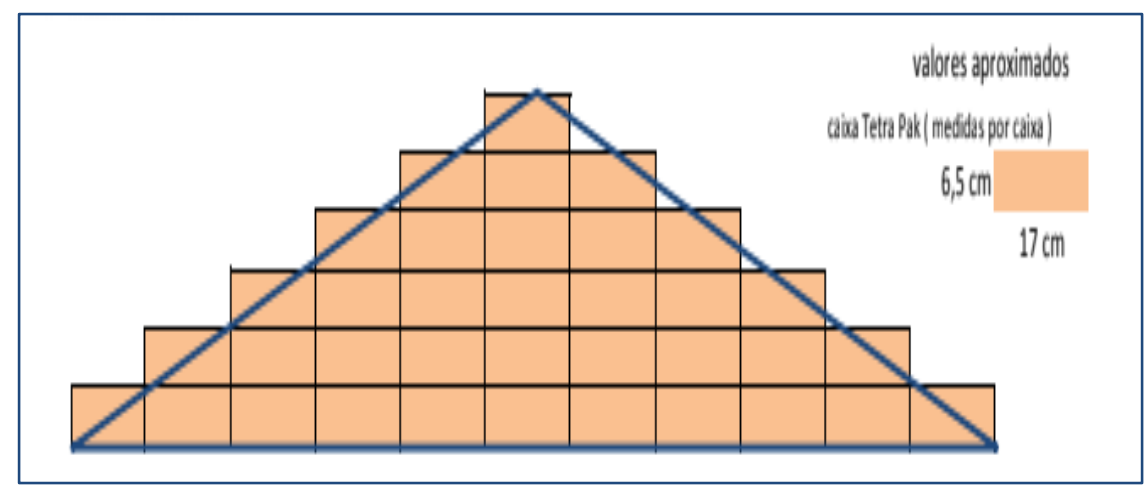

Fonte: acervo do projeto

O processo de contagem do número de caixas de leite para a construção do telhado foi 36. Como são duas partes, necessitou de 72 unidades.

Para a confecção das paredes laterais da casa foi necessários 416 caixas de leite, com base no conteúdo da Figura 4:

Figura 4: Esquema de parede lateral

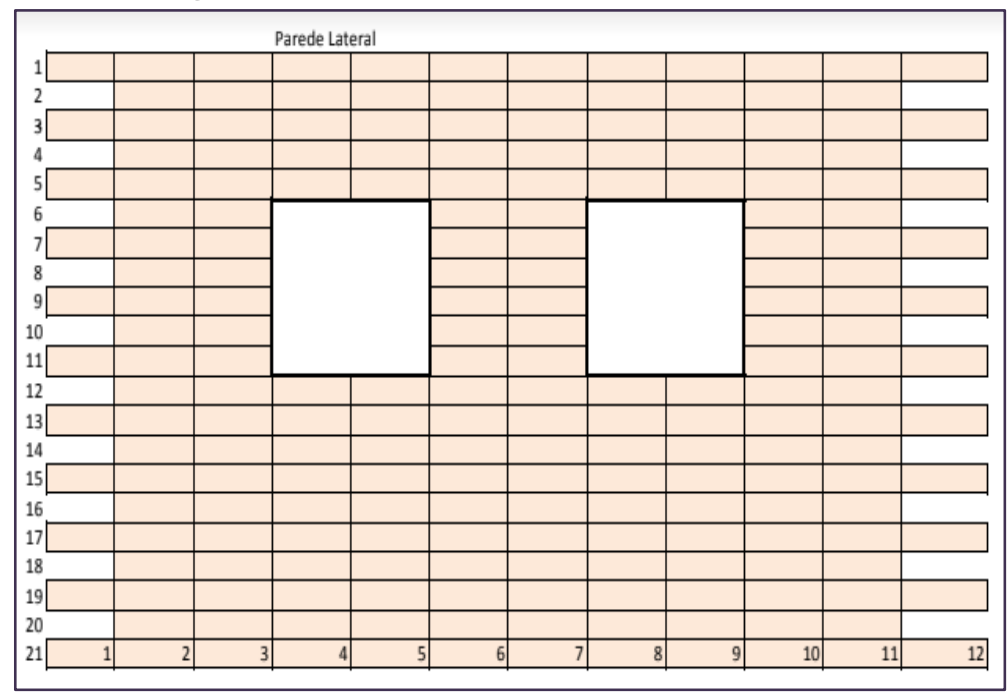

Fonte: acervo do projeto

Os cálculos correspondentes foram:

a) Cada parede: 12 x 2I $=252$ caixas. Devemos subtrair 20 caixas dos encaixes das laterais, ou seja, $252-20=232$ caixas. Como são duas paredes: $232 \times 2=464$ caixas.

b) Janelas: $2 \times 6=12$ caixas. Como são quatro janelas: $12 \times 4=48$ caixas.

O total de caixas nas laterais foi $464-48=416$ caixas. A parede de trás da casa teve seus cálculos efetuados a partir do esboço da Figura 5: 
Figura 5: Parte traseira da caixa

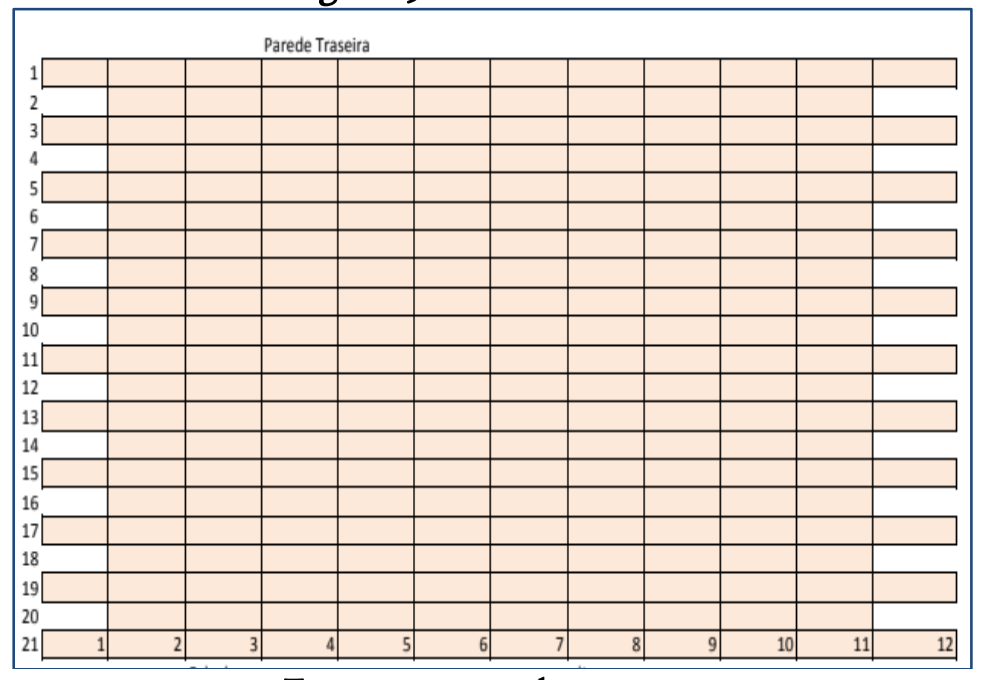

Fonte: acervo do projeto

O número de caixas necessárias foi $\mathrm{I}_{2} \times$ x $2 \mathrm{I}=252$ caixas. Deste valor subtraímos 20 caixas referentes aos encaixes das laterais: $252-20=232$ caixas. Finalmente, o número de unidades de caixas para a construção da parede da frente foi calculado com base na Figura 6:

Figura 6: Frente da casinha

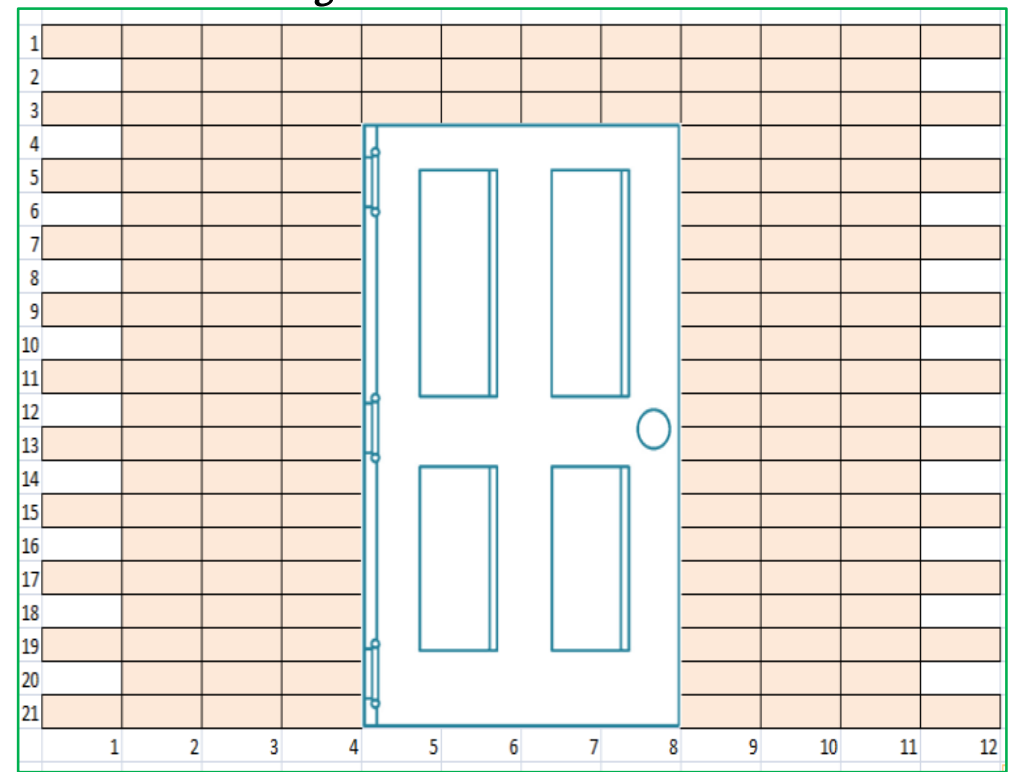

Fonte: acervo do projeto

Os cálculos em questão foram: I2 x 2I $=252$ caixas. Deste valor subtraímos 20 caixas dos encaixes das laterais, ou seja, $252-20=232$ caixas. A porta consumiu $4 \times 18=72$ caixas. Logo, o número de caixas necessárias para a parte frontal da casinha foi $232-72=160$ caixas. Por fim, o total de embalagens de caixas de leite necessárias na construção da 
casinha foi $72+416+232+160=880$ caixas, conforme protocolo escrito de uma aluna (Figura 7):

Figura 7: Cálculo dos tijolos
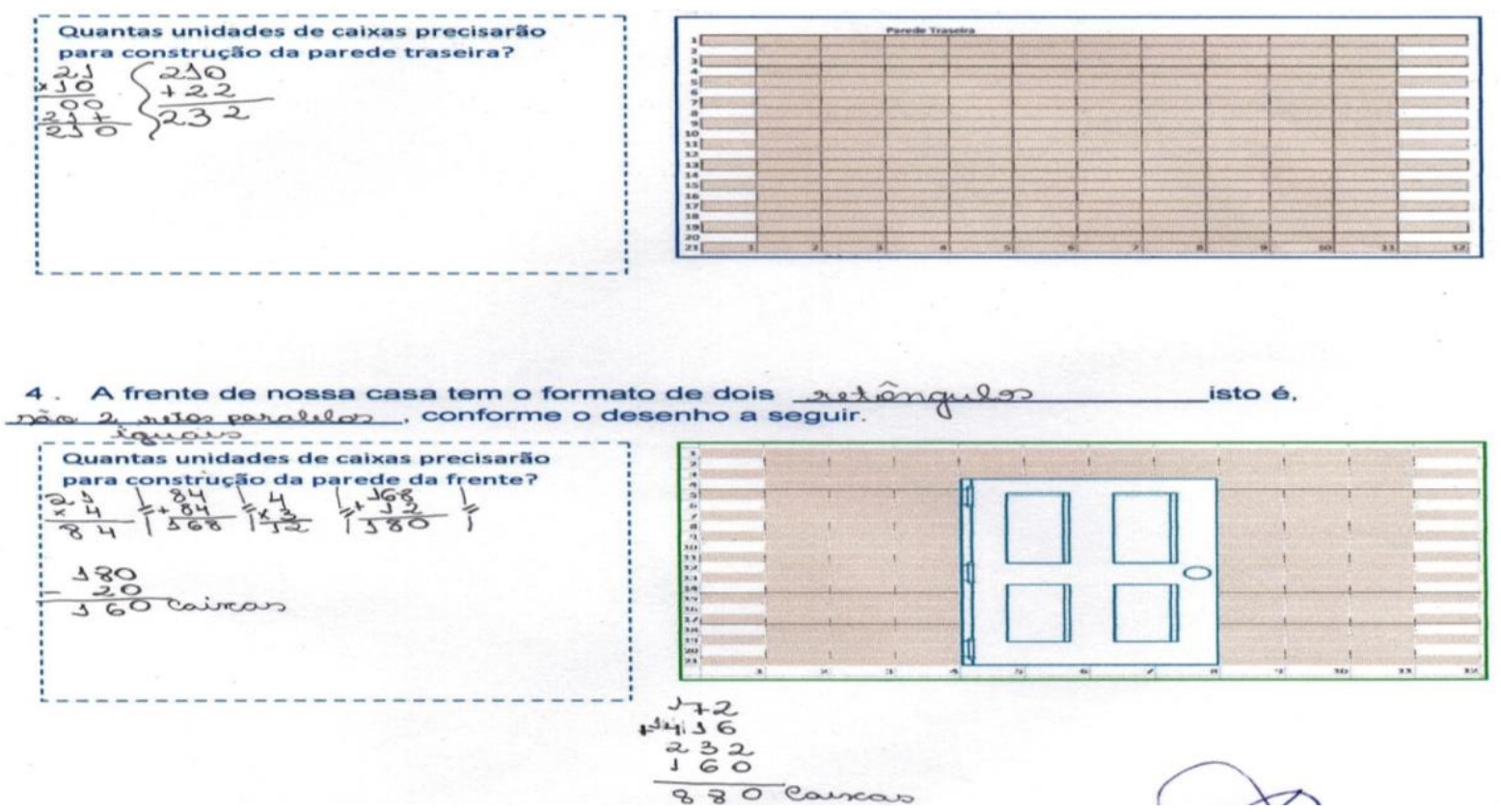

Fonte: acervo do projeto

O conteúdo do protocolo na Figura 7 fez parte de conjunto de tarefas abordadas cuja aprendizagem foi pautada na necessidade do aluno ser capaz de reconhecer e realizar medidas lineares e transformações de unidades, identificar e classificar formas planas e espaciais em contextos concretos e por meio de suas representações em desenhos e em malhas, planificar e reconhecer figuras espaciais, compreender a noção de área e perímetro de uma figura, sabendo calculá-los por meio de recursos de contagem e de decomposição de figuras, além de identificar propriedades de simetria em construções geométricas.

Em termos de dificuldades de aprendizagem o foco foi na noção de grandezas e medidas. As atividades relacionadas à construção da casa demandaram competências e habilidades quanto à distinção de área e perímetro, medidas referentes à largura, comprimento e altura em objeto como a embalagem da caixa de leite.

Nas comunicações estabelecidas entre a professora e os alunos buscamos também melhorar o vocabulário matemático como, por exemplo, na Figura 7 , a aluna relacionou 'duas retas iguais' como forma de caracterizar o retângulo. Abordamos em sala de aula o significado de medidas congruentes, bem como a necessidade de mencionar os quatro ângulos retos internos para definir o retângulo.

O relatório de desempenho na Avaliação de Aprendizagem em Processo - AAP revelou que o menor rendimento dessa turma foi no terceiro bimestre. O percentual médio de acertos nos três bimestres foram $51,82 \%, 62,5 \%$ e 47,14\%, respectivamente. 
A professora-pesquisadora ao corrigir as questões da última AAP com seus alunos no sentido de identificar razões para o referido desempenho constatou que os alunos tiveram dificuldades em relacionar os mesmos conteúdos abordados 'Projeto Edificar' na resolução de questões da avaliação somativa. No olhar de observação da professorapesquisadora, o engajamento com a construção da casa refletiu na falta de diversidade de problemas para os alunos resolverem, comprometendo a aquisição de competências e habilidades requeridas na avaliação somativa, a AAP.

\section{$7^{\circ}$ ANO DO ENSINO FUNDAMENTAL}

Os alunos dessa turma partiram dos cálculos elaborados pelos alunos do 60 ano EF e determinaram as medidas relativas ao comprimento, largura e altura de partes da casa.

O telhado com uma configuração de triângulo isósceles (Figura 3 ) tinha $187 \mathrm{~cm}$ de base, ou seja, II caixas X $17 \mathrm{~cm}=187 \mathrm{~cm}$. A altura desse triângulo valia $39 \mathrm{~cm}$ (6 caixas x 6,5 $\mathrm{cm})$.

As paredes laterais (Figura 4) tinha comprimento de $204 \mathrm{~cm}$ (I2 caixas x $17 \mathrm{~cm}$ ). A altura da parede tinha $136,5 \mathrm{~cm}$, ou seja, 2I caixas $x 6,5 \mathrm{~cm}$. No caso da janela retangular, o seu comprimento é $34 \mathrm{~cm}$ (2 caixas x $17 \mathrm{~cm}$ ) e a altura é $39 \mathrm{~cm}$ (6 caixas x 6,5 cm).

A frente e a parte de trás da casa que foi disposta na Figura 5 e 6 teve comprimento de $204 \mathrm{~cm}$ (I2 caixas X $17 \mathrm{~cm}$ ). A altura dessas paredes tem $136,5 \mathrm{~cm}$, ou seja, 2I caixas x 6,5 $\mathrm{cm}$. No caso da porta, o seu comprimento foi de $68 \mathrm{~cm}$ (4 caixas $x i 7 \mathrm{~cm}$ ) e a altura $117 \mathrm{~cm}$ (I8 caixas $\mathrm{x} 6,5 \mathrm{~cm}$ ).

Feito os cálculos, o próximo passo da professora-autora foi trabalhar com os alunos do $7^{\circ}$ a no a noção de escala como a razão entre a medida de um objeto representado em um desenho e a medida correspondente ao objeto real. $O$ resultado do estudo resultou na planta baixa da casinha, exposta na Figura 8:

Figura 8: Planta baixa da casinha

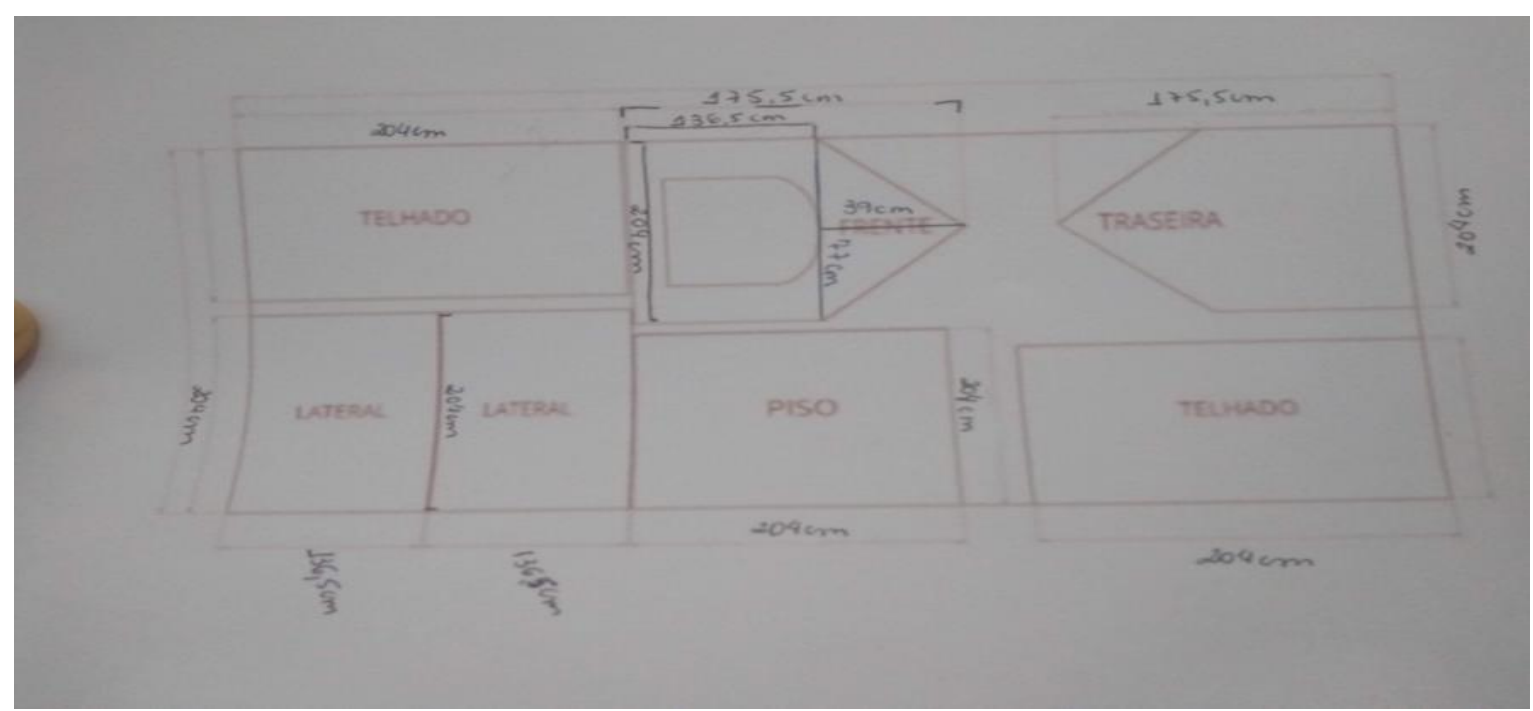

Fonte: acervo do projeto 
O cálculo de razão foi abordado com o setor circular na construção de gráfico de setores. Essa turma ficou responsável pela organização dos dados e representação gráfica e tabular, referente à coleta de embalagens de caixa de leite, de acordo com o conteúdo da Figura 9:

Figura 9: Tabulação da arredação de embalagens

\begin{tabular}{|c|c|c|c|c|}
\hline Censena & Pessoces & Pairas & Anguls & $\%$ \\
\hline 6 - and & 19 & 1419 & $\begin{array}{c}13,9-460 \\
5000\end{array}$ & $13,9 \%$ \\
\hline $7=\operatorname{lno} 0$ & 14 & 82 & $7,6363602736=$ & $7,6 \%$ \\
\hline 8=ans & 9 & 356 & $33,50.360,120,6$ & $33,5 \%$ \\
\hline $9=\operatorname{an} \theta$ & 7 & 58 & $\begin{array}{l}5,4,300 \\
8,949,4\end{array}$ & $5,4 \%$ \\
\hline Psolessoces & 2 & 324 & $\begin{array}{ll}30,3 & -360 \\
90,90 & =9\end{array}$ & $30,3 \%$ \\
\hline ciole 1 & 10 & 100 & $3,48^{-60} \rightarrow 33,48^{\circ}$ & $9,3 \%$ \\
\hline TOTAL & 61 & 1069 & $360 \%$ & $100 \%$ \\
\hline
\end{tabular}

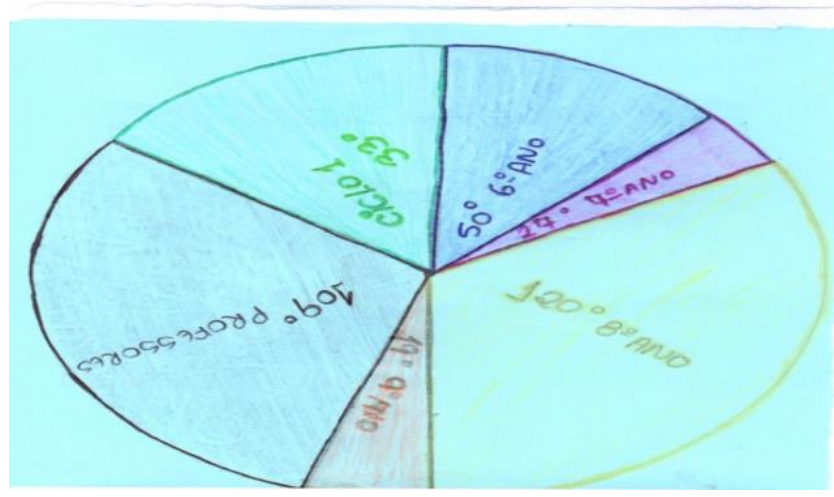

Fonte: acervo do projeto

$\mathrm{Na}$ turma do $7^{\mathrm{o}}$ ano buscamos propor tarefas para desenvolver a capacidade de compreender a ideia de medida de um ângulo (em grau), sabendo operar com medidas de ângulos e usar instrumentos geométricos para construir e medir ângulos. Além disso, compreender e identificar simetria axial e de rotação em figuras geométricas, calcular a soma das medidas dos ângulos internos de um triângulo e estender tal cálculo para polígonos de ' $n$ ' lados, identificar e classificar os poliedros, reconhecer situações que envolvem grandezas direta e inversamente proporcionais e utilizar o conceito de razão em diversos contextos.

No decorrer das tarefas propostas para o 'Projeto Edificar' a pofessora-pesquisadora constatou nessa turma a dificuldade em trabalhar cálculos de razão e proporção pelo fato de terem dificuldade com o conceito de medida. Mais precisamente, os alunos não tinham familiarização com unidades de medidas como o metrô, centímetro e milímetro, assim como a ausência da percepção sobre o que é um metro. Além disso, foi observado dificuldade no manuseio da régua enquanto instrumento de medida. Uma proposta de intervenção pedagógica foi a proposta de uma construção de uma fita métrica como recurso didático para desenvolver a percepção e visualização do quanto é um metro, bem como subdivisão em centímetro e milímetro.

O relatório de desempenho na Avaliação de Aprendizagem em Processo - AAP revelou que o menor rendimento dessa turma, assim como no $6^{\circ}$ ano, foi no terceiro 
bimestre. O percentual médio de acertos nos três bimestres foram 39,91\%, 58,77\% e 38,16\%, respectivamente.

Assim como no $6^{0}$ ano, a correção das questões do $3^{\circ}$ bimestre contidas na AAP, revelou para a professora-pesquisadora a necessidade de propor resolução de problemas com contextos diversificados, pois os alunos apresentaram dificuldades em estabelecer conexões sobre o que havia sido trabalhado no 'Projeto Edificar' com a resolução das questões dessa avaliação somativa.

\section{ANO DO ENSINO FUNDAMENTAL}

Nessa turma com base na planta baixa elaborada pelos alunos do $7^{\circ}$ ano EF, abordamos o seu posicionamento no plano cartesiano. Dentre as tarefas propostas, apresentamos o enunciado de duas delas e a respectiva resolução, com base no protocolo escrito dos alunos.

A primeira tarefa teve a seguinte formulação: Desenhe no Io quadrante a parte frontal da casa e, em seguida, aplique diferentes formas de translação da imagem original nos demais quadrantes. Na Figura Io contemplamos a resolução esperada:

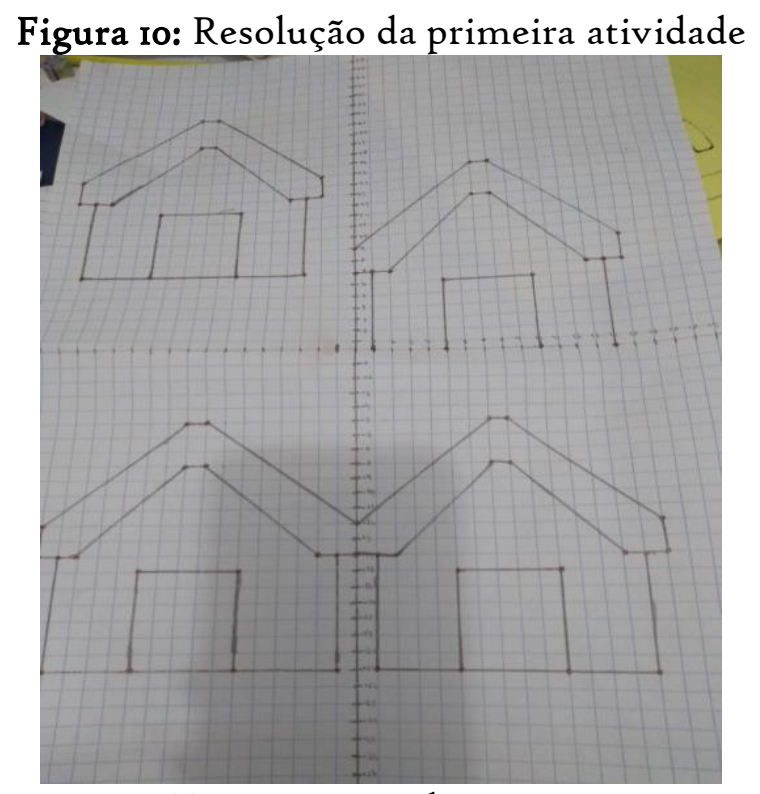

Fonte: acervo do projeto

A segunda tarefa teve a seguinte formulação: Em uma tábua foram fixados, à mesma distância, alguns pregos, formando um Geoplano. Com um barbante forme um desenho da frente da casinha. Aplique a fórmula de Pick para calcular essa área. Na Figura II apresentamos o uso do Geoplano como recurso didático para a representação da vista frontal da casa e na malha quadriculada, além da reprodução dessa figura em escala menor. Esse protocolo contém os procedimentos do cálculo da área considerando as dimensões da figura como grandezas discretas, conforme demanda da fórmula de Pick: 
Figura Ir: Resolução da segunda tarefa

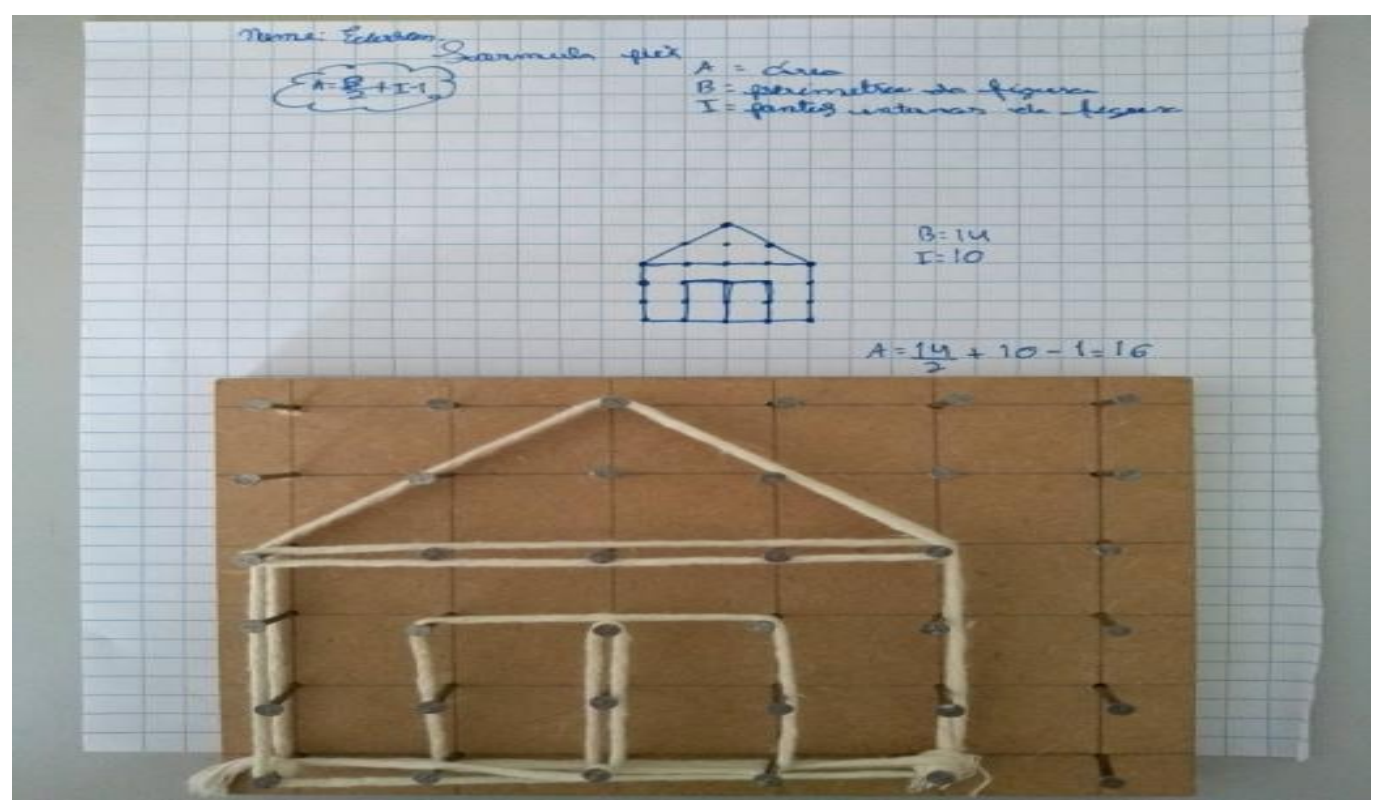

Fonte: acervo do projeto

$\mathrm{Na}$ turma do $8^{\circ}$ ano EF o 'Projeto Edificar' permitiu contemplar tarefas para desenvolver a capacidade de localizar pontos no sistema de coordenadas cartesianas, realizar transformações geométricas no plano e aplicar a fórmula de Pick para um polígono cujos vértices são pontos de uma malha quadriculada. Paralelamente formulamos tarefas envolvendo conteúdos de álgebra para desenvolver as seguintes competências e habilidades: expressar a solução de equações do primeiro grau e explorar problemas, buscando soluções para equações lineares com duas incógnitas.

Essa turma teve muitas situações de fracasso escolar no processo de ensinoaprendizagem de álgebra. No trabalho com projeto praticamente não desenvolvemos atividades com conexões entre geometria e álgebra, exceto a fórmula de Pick. Assim, dividimos o período das aulas de Matemática para abordarmos das competências e habilidades dos conteúdos algébricos citados.

O desempenho da turma na AAP, em termos de média de acertos, atingiu 81,55\% no

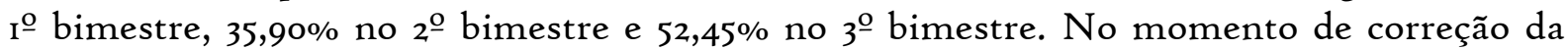
AAP do $3^{\circ}$ bimestre observamos que os alunos poderiam ter tido um desempenho melhor, se o foco da avaliação não fosse área de Álgebra. Do total de 12 questões, apenas três tiveram relação com geometria, sendo duas questões envolvendo figuras bidimensionais inseridas no plano cartesiano e a outra relacionando medidas de lados de um triângulo com o seu perímetro através de expressões algébricas.

\section{9 - ANO DO ENSINO FUNDAMENTAL}


Nessa turma resgatamos os cálculos das dimensões lineares efetuados pelos alunos do $7^{\circ}$ ano e abordamos o Teorema de Pitágoras e o cálculo de área e perímetro de polígonos nas tarefas propostas para a construção da casa.

Paralelamente ao trabalho com o projeto, propomos tarefas para capacitar os alunos na compreensão do significado das razões trigonométricas seno, cosseno e tangente, além de saber utilizá-las para resolver problemas em diferentes contextos.

Em nosso processo contínuo de avaliação constatamos dificuldades de aprendizagem desses alunos no desenvolvimento de cálculos em trigonometria. A dificuldade centralizou nos procedimentos aritméticos envolvendo radiciação, algo muito comum inclusive nas questões objetivas de avaliações somativas como a AAP.

$\mathrm{Na}$ Figura 12 apresentamos um protocolo escrito de uma aluna referente as atividades desenvolvidas no 'Projeto Edificar':

Figura 12: Atividade de uma aluna do $9^{\circ}$ ano EF

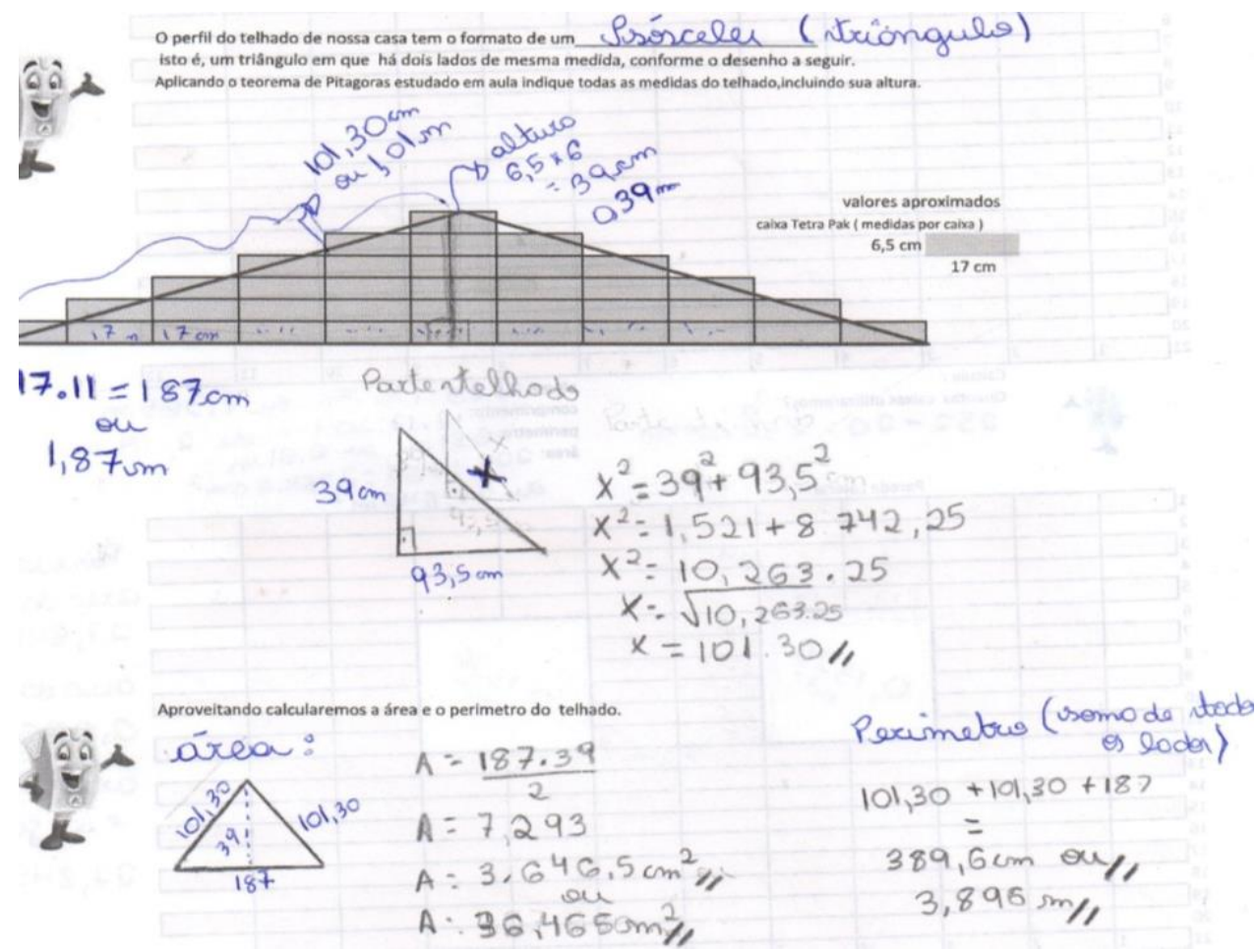

$\mathrm{F}$

onte: acervo do projeto

Além do cálculo de área e perímetro de triângulo retângulo e a aplicação do Teorema de Pitágoras (figura II), outros cálculos foram efetuados com partes da construção da casa e sistematizados em plenária com a professora-pesquisadora e seus alunos, conforme Tabela r: 
Tabela r: Área e perímetro de polígonos

\begin{tabular}{|l|c|c|}
\hline & Área $\left(\mathrm{cm}^{2}\right)$ & Perímetro $(\mathrm{cm})$ \\
\hline Telhado & 3646,5 & 389,6 \\
\hline Janela & 1326 & $\mathrm{I} 46$ \\
\hline Lateral & 25194 & $68 \mathrm{I}$ \\
\hline Porta & 7956 & 370 \\
\hline Parte frontal ou traseira & 19890 & $68 \mathrm{I}$ \\
\hline
\end{tabular}

Fonte: acervo do projeto

Estimulamos os alunos do $9^{\circ}$ ano EF para converter unidades métricas de centímetro para metro e vice-versa, tanto para medidas lineares quanto de superfície. No protocolo apresentado na Figura 12 houve necessidade de intervenção da professorapesquisadora para retomar que a equivalência de I metro ou ioo centímetros não se aplica para conversão de unidades de superfície. Neste sentido, o erro cometido na conversão de $3646,5 \mathrm{~cm}^{2}$ foi abordado e corrigido para $0,36465 \mathrm{~m}^{2}$.

O rendimento médio de acertos dos alunos do $9^{-}$ano EF na AAP de 2018 foi: $40,77 \%$ no $\mathrm{I}^{\mathrm{O}}$ bimestre, $36,11 \%$ no $2^{\mathrm{o}}$ bimestre e $46,88 \%$ no $3^{\mathrm{o}}$ bimestre. Embora o desempenho nessa última avaliação tenha sido o melhor, a correção dessa avaliação com os alunos mostrou que as tarefas propostas em sala de aula sobre trigonometria não foram suficientes para um bom desempenho em três questões da AAP cujos dados foram expressos na forma de raiz quadrada.

Das doze questões da AAP, uma delas envolveu a razão entre duas áreas de triângulos, porém, a medida dos lados estava representada algebricamente. $\mathrm{O}$ cálculo de área foi abordado com problemas relacionados à construção da casa e, por isso, não envolveu medidas algébricas. $\mathrm{Na}$ resolução da referida questão da AAP notamos dificuldades por parte desses alunos, semelhantes àquelas já apresentadas na turma do $8^{\circ}$ ano, quanto a ausência de habilidade em procedimentos algébricos envolvendo as quatro operações fundamentais.

Próximo do término do ano letivo de 2018 , os alunos do $9^{-}$ano EF participaram da avaliação som ativa intitulada Sistema de Avaliação do Rendimento Escolar do Estado de São Paulo -SARESP. De acordo com o boletim da escola, 50\% dos alunos atingiram o nível básico (desenvolvimento parcial dos conteúdos, competências e habilidades requeridos para a série escolar), ı8,8\% atingiram o nível adequado (conhecimentos e domínio dos conteúdos, competências e habilidades requeridos) e 31,2\% estão abaixo do nível básico (domínio insuficiente dos conteúdos, competências e habilidades requeridos para a série escolar) (SÃO PAULO, 2019).

Esse resultado da avaliação som ativa contém informações de desempenho, cuja interpretação deve levar em conta os conteúdos dispostos nas questões, para que possamos realizar uma comparação com a forma que os mesmos foram ou não abordados em sala de aula. Além disso é importante que o professor analise se houve uma distribuição homogênea ou não dos conteúdos na avaliação. Esse exercício de criticidade no conteúdo da avaliação som ativa gera informações que permitem o professor contrapor com o seu 
trabalho em sala de aula, de modo a aprimorar o processo de avaliação formativa para o desenvolvimento de competências e habilidades dos alunos.

\section{CONSIDERAÇÕES FINAIS}

Ao término do trabalho com o 'Projeto Edificar' e a consolidação do seu produto educacional (Figura 13) em exposição, reservamos esta seção do artigo para expor pontos positivos e pontos de melhoria, na perspectiva da professora-pesquisadora.

Figura 13: Finalização e exposição da casa com caixas de leite

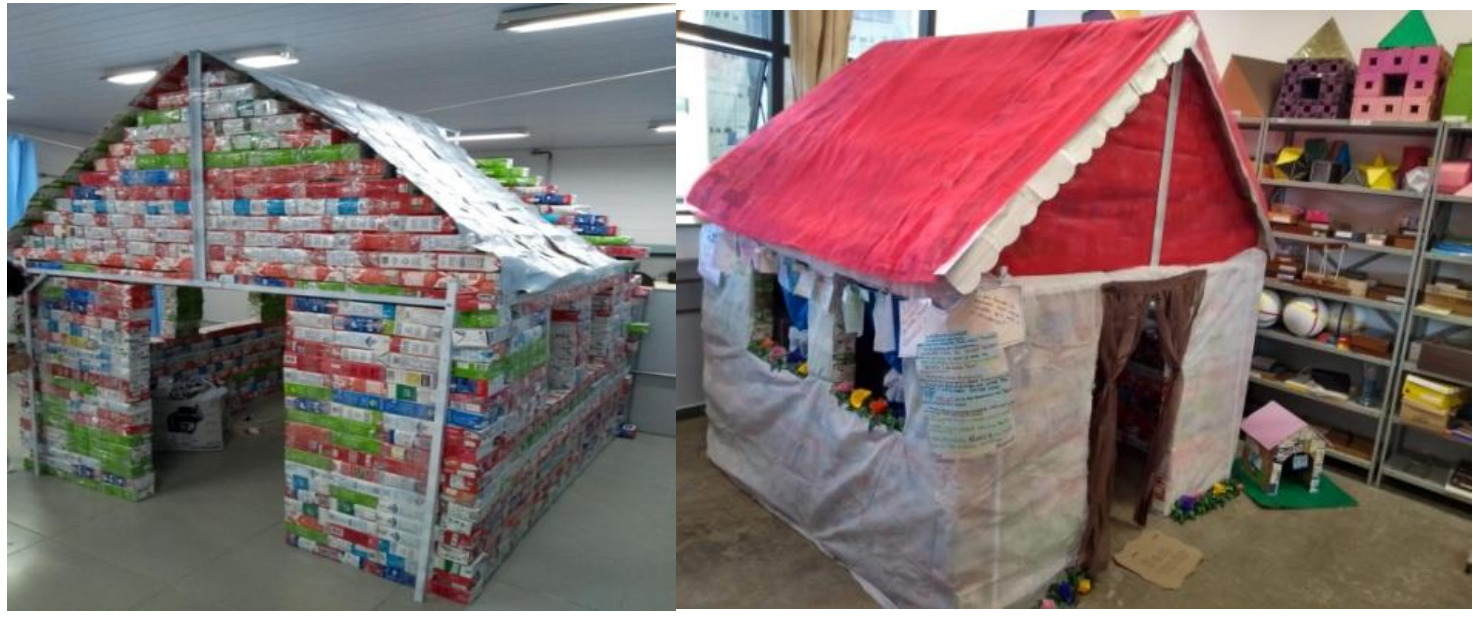

Fonte: acervo do projeto

O trabalho com projeto foi uma experiência diferente na carreira da professorapesquisadora, bem como para os alunos diretamente envolvidos e a gestão escolar.

No decorrer de um semestre letivo houve impactos na aprendizagem dos alunos, por conta do processo de avaliação contínua, em cada uma das turmas. De modo geral, a grande dificuldade nesse processo ensino-aprendizagem foi o despertar do senso de trabalho em equipe, já que cada uma das turmas dos anos finais do Ensino Fundamental tinha tarefas específicas para ajudar na consolidação da construção da casa, o que gerou uma relação de dependência entre elas para que ocorresse a finalização do projeto.

$\mathrm{O} 6^{\mathrm{o}}$ e $7^{\mathrm{o}}$ ano do Ensino Fundamental eram turmas que exigiu da professorapesquisadora uma atenção maior no decorrer desse projeto devido a faixa etária dos alunos, a qual ainda é permeada por uma ampla relação de dependência com os adultos. A participação dos responsáveis por esses alunos na arrecadação das embalagens de caixas de leite, na cobrança do cumprimento de tarefas escolares e frequência nas aulas contribuiu de forma positiva na aquisição de responsabilidades escolares em nível individual e coletivo.

$\mathrm{Na}$ turma do $8^{-}$e $9^{-}$ano do Ensino Fundamental foi possível estabelecer uma relação entre a professora-pesquisadora e seus alunos com mais cumplicidade e dinâmica 
quanto às demandas do 'Projeto Edificar'. Houve casos de alunos destas turmas que exerceram papel de monitores de alunos do $6^{0}$ e $7^{\circ}$ ano.

À medida que íamos cumprindo o cronograma de conteúdos previsto no decorrer do

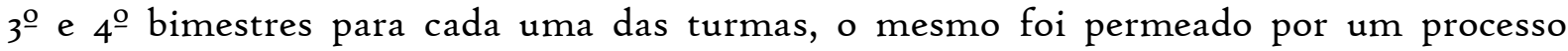
contínuo de avaliação que envolveu a correção de todas as atividades desenvolvidas tanto para a construção da casa, quanto para conteúdos escolares que não puderam ser envolvidos no 'Projeto Edificar'. Concomitantemente, houve atenção por parte da professora-pesquisadora no planejamento de tarefas e abordagem de conteúdos para os alunos, levando em conta as competências e habilidades possíveis de serem cobradas na Avaliação de Aprendizagem em Processo - AAP no término do $3^{\circ}$ bimestre.

No que diz respeito ao que foi proposto como tarefas para a construção da casa foi notório o comprometimento dos alunos pelo fato de estarem desenvolvendo atividades familiares ao cotidiano de muitos estudantes devido à profissão dos familiares, além de constituir-se tarefas que envolveram a análise de erros, incertezas, construções de hipóteses, entre outras, o que os motivou para os estudos com o propósito de verem a casa pronta, ou seja, construída.

De modo geral, as dúvidas dos alunos e resultados de avaliação formativa e som ativa apontaram a necessidade de reforçar o desenvolvimento de competências e habilidades no estudo de grandezas e medidas, equação do Io grau e operações com números irracionais expressos por raiz quadrada para a resolução de problemas com razões trigonométricas.

No decorrer do desenvolvimento do Projeto Edificar a dificuldade de flexibilidade no cumprimento dos conteúdos programáticos por conta das cobranças de desempenho quantitativo advindo dos diversos sistemas de avaliação som ativa como a AAP e o Sistema de Avaliação de Rendimento Escolar do Estado de São Paulo - SARESP, para o 9o ano EF, comprometeu uma possível equidade na abordagem de determinados conteúdos escolares, como já citamos.

Por conta da construção da casa, a professora-pesquisadora dedicou mais tempo do número de aulas de Matemática para conteúdos presentes no trabalho com o Projeto Edificar, em detrimento de outros conteúdos, principalmente envolvendo a álgebra.

Como sugestão no investimento de novas pesquisas, deve-se levar em conta que a educação pública tem sido norteada por sistemas de avaliação externa (avaliação som ativa) que ocorrem bimestralmente, portanto, é interessante planejar o trabalho com projetos de ensino com um período menor. Tal atitude pode permitir ao professor administrar melhor o desenvolvimento de competências e habilidade tanto no processo de avaliação formativa quanto som ativa, minimizando situações de fracasso escolar.

\section{REFERÊNCIAS}

BRASIL, Ministério da Educação. Parâmetros Curriculares Nacionais: Matemática (Ensino Fundamental II). Brasília: MEC/SEF, 1998. i48p. 
BRASIL. Ministério da Educação. Base Nacional Comum Curricular - BNCC: Educação é a base. Brasília: MEC, 2018. 6oop. Disponível em: $\langle$ http://basenacionalcomum.mec.gov.br/images/BNCC_EI_EF_IIO5I8_versaofinal_site.pdf >. Acesso em: i7 ab. 2020.

CARVALHO, D.L. Trabalho com projetos no ensino e na aprendizagem de estatística: benefícios, problemas, limitações. Educação Matemática em Revista, SBEM-RS, a no ıo, v.I, n.Io, pp.83-93, 2009.

CENPEC - Centro de Estudos e Pesquisas em Educação, Cultura e Ação Comunitária. Currículos para os anos finais do Ensino Fundamental: concepções, modos de implantação e usos. São Paulo: Cenpec, 2015. Disponível em: 〈http://www.cenpec.org.br/

wp-content/uploads/2015/o9/Relatorio_Pesquisa_Curriculos_EF2_Final.pdf $>$. Acesso em: I9 jul. 2021.

CHUEIRI, M.S.F. Concepções sobre a Avaliação Escolar. Estudos em Avaliação Educacional, Associação Brasileira de Avaliação Educacional - Abave, v.19, n.39, pp.49-64, 2008.

CRESWELL, J. W. W. Projeto de pesquisa: métodos qualitativo, quantitativo e misto. $2^{-}$ ed. Porto Alegre: Bookman, 2 oro.

FORNER, D. S.G.; TREVISOL, M.T.C. Significados e funções da avaliação da aprendizagem escolar. Roteiro, Joaçaba, v. 37, n. 2, p. 243-264, jul./dez., 2012.

GIORDANO, C.C.; SILVA, D.S.C. Metodologias ativas em Educação Matemática: a abordagem por meio de projetos na Educação Estatística. Revista de Produção Discente em Educação Matemática, São Paulo, v. 6, n. 2, p. 78-89, 2017.

PONTE, J. P. Estudos de caso em educação matemática. Bolema, Rio Claro, n.25,p.105-132, 2006.

RECORD TV PAULISTA. Professora de Sorocaba ensina matemática de um jeito diferente $e$ melhora desempenho dos alunos. Disponível em: $\langle$ https://www.youtube.com/watch?v=zS7pMogVO24\&t=64s >. Acesso em: 19 jul.2021.

SÃO PAULO. Secretaria da Educação. Currículo do Estado de São Paulo: Matemática e suas tecnologias - Ensino Fundamental (Ciclo II) e Ensino Médio. Coordenação de área: Nilson José Machado. I ${ }^{\mathrm{a}}$ ed. atual. São Paulo, SEE, 2012. 72p.

SÃO PAULO. Sistema de Avaliação de Rendimento Escolar do Estado de São PauloSARESP 2018: boletim da Escola Estadual Professor Flávio Gagliardi. São Paulo, SEE, 2019.Disponível em: <http://saresp.fde.sp.gov.br/Boletins.aspx >. Acesso em: 19 jul.2021. 